was always rewarded; the other stimulus of a given pair was not. In the extradimensional shifts, position was always irrelevant. Of the eight problems, four were reversal and four were extradimensional shifts. The extradimensional and reversal shifts were randomly interspersed. During differential training, 30 noncorrection trials were presented each day until a criterion of at least nine correct responses in both of two consecutive 10-trial blocks was reached.

All Ss were subsequently trained on a two-choice pattern form discrimination ( $\mathrm{x}$ vs plus). Training was continued until $S$ made at least 27 correct responses within a 30-trial session or received a total of 600 trials.

\section{RESULTS}

Preoperative Preference Testing

Dimensional preferences with object and pattern stimuli as reflected by the number of problems on which one cue was consistently chosen are shown in Fig. 1. Analyses of variance (Friedman test) on the ranked preference scores were performed separately for the object and pattern tests. A significant difference $\left(\chi_{r}^{2}=12.02, \mathrm{df}=2, \mathrm{p}<.01\right)$ was disclosed for the patterns, but not for the objects. Difference scores of the individual Ss indicated that position was chosen more ( $<<.01$, Wilcoxon rank-sum) and form less $(\mathrm{p}<.05)$ in patterns than in objects.

Postoperative Preference Testing

Changes in dimensional preferences with the object stimuli were examined by computing preoperative-postoperative difference scores for each $S$. With a postoperative increase represented by a positive number, the mean changes for form, color, and position, respectively, were $+2.7 \%,+0.4 \%$, and $-3.1 \%$ for normal $S s$ and

Table 1

Mean Trials to Criterion on Shift Problems

\begin{tabular}{llccl}
\hline Group & \multicolumn{1}{c}{ Shift } & Color & Form Position \\
\hline Normal & $\begin{array}{l}\text { Reversal } \\
\text { Extra- }\end{array}$ & 18.3 & 11.7 & - \\
& $\begin{array}{l}\text { dimensional } \\
\text { Reversal }\end{array}$ & 30.0 & 10.0 & - \\
Infero- & $\begin{array}{l}\text { Extra- } \\
\text { temporal dimensional }\end{array}$ & 33.9 & 20.0 & 57.5 \\
\hline
\end{tabular}

$-17.5 \%,-2.6 \%$, and $+20.1 \%$ for inferotemporal Ss. The only difference between groups supported by statistical test was a greater change toward position for the inferotemporal $S s$ than for the normals ( $p=.05$, one-tail Mann-Whitney).

Differential Training

Table 1 gives the mean scores on the reversal and extradimensional shift problems in the different dimensions for the two groups. Although the lesion main effect failed to reach a reliable level in a lesion by shift by problem analysis of variance, the lesion by shift interaction was significant $(\mathrm{F}=8.7, \quad \mathrm{df}=1 / 4, \quad \mathrm{p}<.05) . \quad$ Closer inspection of the data, however, revealed that this result was due to the high scores of the inferotemporal Ss on reversal shifts after position preferences, a type of reversal which none of the control animals happened to receive. When reversal shifts within color and form were considered alone, there was no significant difference between the groups. The problem main effect also reached a reliable level $(F=4.6, d f=3 / 12$, $\mathrm{p}<.05$ ), indicating interproblem improvement for both groups.

Whereas all of the normal Ss reached criterion on the pattern form discrimination (range: 80-270 trials), none of the Ss with inferotemporal lesions succeeded in meeting the criterion within 600 trials. DISCUSSION

On discrimination training with the pattern forms (X vs plus), the inferotemporal $S s$ showed the expected deficit in acquisition. With the object stimuli, however (either reversal or extradimensional shifts), these animals were able to attend to all dimensions and learn problems at a normal rate. The results of the preference tests indicated that the dimensional relationships were quite different, depending upon whether the stimuli were raised forms (objects) or printed forms (patterns). In the former case, position, color, and form were equally preferred. With the patterns, position was by far the most salient dimension, while form appeared to exert little control over the organism's performance.

These results may be helpful in understanding the impairment of inferotemporal $S s$ in learning visual discriminations. Even though inferotemporal animals displayed some tendency to shift their preferences to position, their ability to learn to attend to all dimensions in objects is not surprising in light of the fact that none of the dimensions appeared in the preference testing to be of disproportionate strength. The magnitude of the temporal deficit in solving patterns, however, suggests that these Ss may have difficulty in learning to attend to a dimension (e.g., form) when another extremely strong dimension (e.g., position) is present and irrelevant.

\section{RFFERENCES}

BUTTER, C. M., MISHKIN, M., \& ROSVOLD, H. E. Stimulus generalization in monkeys with interotemporal and lateral occipital lesions. In D. J. Mostofsky (Ed.), Stimulus generalization. Stanford: Stanford University Press, 1965. Pp. 119-133.

MISHKIN, M., Visual discrimination performance following partial ablations of the temporal lobe: II. Ventral surface vs hippocampus. Journal of Comparative and Physiological Psychology, 1954, 47, 187-193.

ROTHBLAT, L. A., \& WILSON, W. A., JR. Intradimensional and extradimensional shifts in the monkey within and across sensory modalities. Journal of Comparative \& Physiological Psychology, 1968, 66, 549-553. WEISKRANTZ, L., \& COWEY, A. Striate cortex lesions and visual acuity of the rhesus monkey. Journal of Comparative \& Physiological Psychology, 1963, 56, 225-231. NOTES

1. This study was supported in part by United State Public Health Service Grant MH 10972 to the second author. A preliminary report of the research was presented at the annual meetings of the Eastern Psychological Association, 1968.

2. Now at Department of Psychiatry (Neuropsychology), Stanford University, Palo Alto, California 94304.

\title{
Counterconditioning and fear reduction in the rat ${ }^{1}$
}

\author{
BERNARD KLEIN, The College of William \\ and Mary, Williamsburg, Va. 23185
}

Three groups of rats were conditioned to escape shock in a two-compartment Miller box. One group was then confined in the shock compartment with food, the second confined without food, and the third not confined at all. Confinement with food was significantly more effective in reducing fear than confinement without food or no confinement, as measured by latency of escape from the shock compartment during extinction trials. However, both confinement with food and confinement without food were equally effective in reducing fear as measured by avoidance of 
the shock compartment during postconditioning preference trials.

Feeding an organism in a fear-producing situation has generally been viewed as having a fear-reducing effect. This method has been called counterconditioning, with the typical paradigm consisting of the introduction of a positive reinforcer (i.e., food) in the fear-producing environment.

Studies by Lane (1954) and Nelson (1966) have yielded inconsistent results in application of this technique. Lane (1954) gave rats shock-escape training in the Miller-Mowrer apparatus, and then confined them in the shock compartment with or without food. Using latency of running out of the fear compartment as a measure of residual fear, he found that those Ss fed during corfinement ran out more slowly during test trials than did Ss that were not fed.

Nelson (1966) did not feed the counterconditioned group intermittently as did Lane, but fed them by placing them directly over a dish of food. This was done to minimize the conditioning of approach responses that might be incompatible with the measurement of fear. In comparison of latency scores after counterconditioning, confinement with or without food was found to be more fear-reducing than no confinement at all. However, more fear reduction was found in the group that was not fed during confinement than in the group that was fed. It was concluded that exposure, and not counterconditioning, was the critical variable in the food-fear relationship.

The present study was designed to determine the effect of counterconditioning on fear extinction using two measures of residual fear: latency of escape from the shock compartment during postconditioning extinction trials, and avoidance of the shock compartment during postconditioning preference trials.

SUBJECTS AND APPARATUS

The Ss were 14 male albino rats. They were trained in a modified Miller-Mowrer device having two compartments, each $15 \times 8 \times 11$ in. One was white with a grid floor and a white striped Plexiglas top; the other was black with a solid floor and a black striped Plexiglas top. Both floors were hinged at the end furthest from the opposite compartment. The two compartments were separated by a Plexiglas door that could be raised and lowered manually. Microswitches activated counters that recorded Ss' entries into and exits from each chamber. A Grason-Stadler grid scrambler was used in conjunction with a shock source of $2.5 \mathrm{~mA}$.

\section{PROCEDURE}

The experimental procedure was broken into the following steps: (a) Ss were randomly assigned to three groups, and a deprivation schedule was started. They were fed $10 \mathrm{~g}$ of powdered Purina Lab Chow every $24 \mathrm{~h}$ in a Petrie dish in the home cage. Water was available ad lib, and overhead fluorescent lamps were on continuously. (b) Preference trials began 14 days later. Testing was done during normal feeding time, and Ss were fed at completion of the procedure. They were placed in the middle of the white compartment facing the open door, and allowed free access between the two compartments. All groups received one 15-min trial, with time spent on each side recorded. At completion, Ss were deprived of food for $48 \mathrm{~h}$. (c) Shock-escape training than began, with Ss placed in the middle of the shock compartment facing the closed door. Sixty seconds later, shock was applied simultaneously with the opening of the door, and remained on until they ran to the safe side. The door was then closed; Ss were confined for $60 \mathrm{sec}$ and then returned to their home cages and fed. All groups received five trials with a $24 \mathrm{~h}$ intertrial interval, and latency of escape was recorded. At completion of training, Ss were again f o od-deprived for $48 \mathrm{~h}$. (d) Counterconditioning procedures were then started. In the no-confinement group (NC), Ss were handled for $10 \mathrm{~min}$, and then returned to their home cages and fed. In the confinement-with-food group (CF), Ss were placed in the middle of the shock compartment facing the closed door, directly over a dish containing $10 \mathrm{~g}$ of powdered chow, and allowed 10 min to eat. They were then removed to their home cages. In the confinement-no-food group (CNF), Ss were placed in the middle of the shock compartment facing the closed door, confined for $10 \mathrm{~min}$, and then returned to their home cages and fed. Each group received five trials with a $24 \mathrm{~h}$ intertrial interval. Ss were again food-deprived for $48 \mathrm{~h}$. (e) Extinction trials then began, in which Ss were placed in the middle of the shock compartment facing the open door and allowed to escape to the safe side. Upon entry, they were removed to their home cages and fed. Each group received five trials with a 2-min intertrial interval. Latency of escape was again recorded, and Ss were again food-deprived for $48 \mathrm{~h}$.(f) Postconditioning preference trials were then started. Ss were placed in the middle of the shock compartment facing the open door and allowed free access between the two compartments. All groups received one 15 -min trial, in which time spent on either side was recorded. They were then removed to their home cages and fed.

\section{RESULTS}

No significant differences were found in initial preference in time spent on the white side between groups $(\mathrm{F}=.412, \mathrm{df}=2 / 11$, p > .05). Extinction scores show a significant difference between groups $(\mathrm{F}=10.28$, df $=2 / 11, \mathrm{p}<.05)$. Latencies of the $C F$ group were significantly greater than those of the NC group $(t=5.06, d f=8$, $p<.05)$ and the CNF group $(t=4.21$, $\mathrm{df}=7, \mathrm{p}<.05)$. No significant difference was found between the NC group and the CNF group $(t=.36, d f=7, p>.05)$. Postconditioning preference trials show a significant difference between groups for the white compartment $(F=33.19$, df $=2 / 11, p<.05)$. Significant differences were found between Groups CF and NC $(t=11.09, \mathrm{df}=8, \mathrm{p}<.05)$, and between Groups CNF and $\mathrm{NC}(\mathrm{t}=2.76$, df $=8$, $\mathrm{p}<.05$ ). No significant difference was found between Groups $\mathrm{CF}$ and $\mathrm{CNF}$ $(t=.03, d t=7, p>.05)$.

\section{DISCUSSION}

Since all groups showed no initial preference for either side of the apparatus, differences among groups in extinction and posstconditioning preference trials must be attributed to the experimental procedure.

On the extinction parameter, results are consistent with those obtained by Lane (1954), but conflict with results obtained by Nelson (1966). It is clear that the CF group was less fearful of the shock compartment after counterconditioning than either the $\mathrm{CNF}$ or NC groups. No significant difference was found between the latter two conditions in reducing fear.

The postconditioning preference measure shows that the CF and CNF conditions were significantly more effective in reducing fear than was the NC condition. Ss in both of these groups spent a significantly greater amount or ume in the shock compartment during this time than did those in the NC group. However, no significant difference was found between Groups CF and CNF. This indicates that, while the counterconditioned group was less fearful than the no-confinement group, the technique was no more effective in reducing fear than was the confinement-without-food condition.

These results indicate that extinction was more sensitive in measuring residual fear than was postconditioning preference, dictating the necessity for further research along these lines.

\section{REFERENCES}

LANE, B. R. Reduction of anxiety under three experimental conditions. Unpublished doctoral dissertation, Columbia University Teachers' College, 1954.

NELSON, F. Effects of two counterconditioning procedures on the extinction of fear. Journal of Comparative \& Physiological Psychology, 1966. 62, 208-213.

\section{NOTE}

1. The author wishes to thank Peter L. Derks and Herbert Friedman for their valuable suggestions and criticisms of this study. 